\title{
BREVES NOTAS SOBRE A POLÊMICA QUE MEDEIA AS CONSTRUÇÕES TEÓRICAS DE H.L.A. HART E RONALD DWORKIN
}

\author{
Umberto Paulini*
}

\begin{abstract}
RESUMO
O presente ensaio tem como objetivo propiciar ao leitor uma sucinta análise da polêmica levada a efeito por dois importantes pensadores da seara jurídica: Herbert Hart e Ronald Dworkin. Para tanto, analisar-se-á, em um primeiro momento, os conceitos centrais da teoria de Hart, como o sistema jurídico enquanto união de regras primárias e secundárias, a idéia de obrigação como elemento fundamental para a compreensão do aspecto interno do direito, o papel da regra de reconhecimento dentro do ordenamento jurídico, e, por fim, a tese da discricionariedade judicial. Logo em seguida, serão estudadas as críticas que Dworkin opõe a esta metodologia de compreensão do mundo jurídico, formulando, então, sua própria proposta de apreensão do direito, fulcrada em três teses fundamentais: a tese dos direitos, a tese da resposta correta e a tese do direito como integridade. Ao final, serão destacados os pontos positivos e negativos de cada teoria, evidenciando a sua contribuição para o atual estágio de compreensão do fenômeno jurídico.

Palavras-chave: Teoria do Direito; Contraponto Teórico; Herbert Hart; Ronald Dworkin.
\end{abstract}

Sumário: 1 INTRÓITO; 2 H. L. A. HART: O CONCEITO DE DIREITO; 3 RONALD DWORKIN: O IMPÉRIO DO DIREITO; 4 À GUISA DE CONCLUSÃO: ASPECTOS NEGATIVOS E POSITIVOS DE CADA PROPOSTA; 5 REFERÊNCIAS.

* Mestrando em Direito das Relações Sociais pela UFPR. Endereço eletrônico: beto_ufpr@yahoo.com.br 


\section{INTRÓITO}

Se, de fato, não restam dúvidas de que a atenção conferida pelos juristas à pergunta "O que é direito?" não encontra paralelo em qualquer outro ramo do conhecimento estudado academicamente de maneira autônoma, não sem surpresa é possível encarar a assertiva de que os operadores jurídicos, ao adentrar este novo milênio, abandonaram definitivamente a pretensão de responder a pergunta acerca da verdadeira natureza do direito em todas as épocas e lugares. Afirma-se, em síntese, que o conceito de direito está agora atrelado às contingências históricas do modelo jurídico-político vigente e, por isso, é dotado de caráter substancial, vinculado aos anseios da sociedade.

Assim, sabendo que nesta nova fase do pensamento jurídico vários autores têm como meta explícita a construção de um modelo de direito abertamente superador do positivismo, convém voltar os olhos para a controvérsia instaurada entre as construções teóricas de dois grandes juristas, cuja riqueza de detalhes ofereceu as bases para a compreensão, ao menos em grande parte, do que atualmente se entende por direito.

\section{H. L. A. HART: O CONCEITO DE DIREITO}

Hart é, sem sombra de dúvidas, um dos maiores representantes do positivismo dentro do common law. Sem embargo, com o legítimo intuito de não incorrer num equivoco freqüentemente reproduzido na imensa maioria dos manuais voltados ao estudo da chamada "Teoria Geral do Direito", convém esclarecer que a teoria hartiana não representa um mero reflexo daquilo que Kelsen significa para o direito europeu continental ou civil law.

Em verdade, Hart pode ser considerado como um positivista moderado, daí 
porque alguns autores que se debruçaram sobre suas teorizações classificam suas idéias sob a alcunha de "positivismo light". ${ }^{1}$ Atente-se, neste sentido, que o referido autor dedica uma especial atenção ao aspecto interno do sistema jurídico, ou seja, a correta compreensão do fenômeno jurídico perpassaria necessariamente a visão do participante da comunidade. Dento de sua obra, Hart encara o direito como um fato institucional, fazendo-se necessário que as pessoas aceitem uma determinada regra como norma de comportamento e a tenham como um padrão geral aceito pelo grupo, o que, de maneira alguma, pode ser vislumbrado nas teorizações de Hans Kelsen.

Partindo dos pressupostos enunciados pela Filosofia da Linguagem Ordinária - sobretudo por autores como Wittgenstein, Saussure e Austin - Hart logra reconhecer uma maior abertura do ordenamento jurídico. O Direito, analisado como prática institucional, no qual a perspectiva hermenêutica desempenha papel fundamental, não pode ser compreendido como um sistema fechado, como uma realidade em si mesma. Por isso mesmo, é possível afirmar que Hart se distancia do modelo positivista clássico, sendo inclusive reconhecido por Ronald Dworkin, seu crítico mais ferrenho, como um filósofo moral, que teria "um instinto para problemas de princípios e uma lucidez maravilhosa para expô-los". ${ }^{2}$

Analisar-se-á, ao longo deste artigo, porém de maneira bastante simples, alguns dos pontos fundamentais da teoria Hart acerca do fenômeno jurídico, bem como suas principais conseqüências e desdobramentos.

${ }^{1}$ KOZICKI, Katya. Conflito e estabilização: comprometendo radicalmente a aplicação do direito com a democracia nas sociedades contemporâneas. Universidade Federal de Santa Catarina, Florianópolis, 2000. Tese (Doutorado em Filosofia do Estado e do Direito), p. 174.

${ }^{2}$ DWORIN, Ronald. Levando os direitos a sério. Trad. Nelson Boeira. São Paulo: Martins Fontes, 2002, p. 12. 


\subsection{O SISTEMA JURÍDICO COMO UNIÃO DE NORMAS PRIMÁRIAS E SECUNDÁRIAS}

Considerando as dificuldades em conceituar Direito, Hart propõe um novo ponto de partida para a compreensão do fenômeno jurídico, assentado na premissa de que o ordenamento jurídico é constituído por dois tipos de normas: (i) primárias, que prescrevem que os seres humanos façam ou omitam certas ações; e (ii) secundárias, que permitem a introdução de novas regras primárias, a extinção ou modificação das regras anteriores e o estabelecimento de um procedimento de controle de aplicação das regras existentes.

Para chegar a tal conclusão, Hart afirma ser possível imaginar uma sociedade sem tribunais, juízes ou funcionários de qualquer tipo, isto é, uma comunidade primitiva, cuja estrutura social seria formada tão-somente por regras primárias de obrigação e o único meio de controle social é justamente a atitude geral do grupo face às pautas de comportamento estabelecidas. É obvio que as regras primárias assim agrupadas jamais formarão um sistema coeso, apresentando-se, na prática, inúmeras deficiências quanto à identificação das regras e seus efetivos, motivo pelo qual se viveria num estado de incerteza. Ademais, o caráter estático das regras faria com que suas modificações estivessem adstritas a um lento processo de evolução social. Por fim, tem-se o problema da ineficácia da pressão social difusa pela qual se fazem observar as regras vigentes. ${ }^{3}$

As soluções para as questões levantadas estão fundadas na idéia de que esta estrutura social baseada apenas em regras primárias de obrigação (que impõe um dever), terá de incorporar ao seu sistema jurídico primitivo regras secundárias de um tipo bastante diferente: (i) a regra de reconhecimento, que resolve o problema da incerteza; (ii) as regras de alteração, que resolvem o problema do caráter estático das regras; e (iii) as regras de julgamento, que resolvem o problema da insuficiência da pressão social difusa.

\footnotetext{
${ }^{3}$ HART, H. L. A. O conceito de direito. Trad. A. Ribeiro Mendes. 2. ed. Lisboa: Caloustre Gulbenkian, 1994, p. 101-103.
} 
O remédio para o regime das incertezas estabelecido pela vigência exclusiva de regras primárias consiste na introdução de uma "regra de reconhecimento" dentro do sistema jurídico, pois esta "especificará algum aspecto ou aspectos cuja existência de uma dada regra é tomada como uma indicação afirmativa e concludente de que é uma regra do grupo que deve ser apoiada pela pressão social que ele exerce". ${ }^{4}$ Importante ressaltar que a função desta regra de reconhecimento é a referência ao texto legal como dotado de autoridade, o que, ao mesmo tempo, elimina qualquer dúvida acerca da própria existência da regra.

Já a solução para a morosidade na alteração do direito é apresentada sob a forma de "regras de modificação" que "conferem poder a um indivíduo ou a um grupo de indivíduos para introduzir novas regras primárias para a conduta da vida do grupo, ou de certa classe dentro dele, e para eliminar regras antigas". ${ }^{5}$ Somente assim se pode conceber as idéias de criação e derrogação de normas por via legislativa, lembrando que as regras de alteração podem ser relativamente complexas: é comum chegar-se até mesmo a especificar quem pode legislar sob um determinado assunto e que procedimento deve seguir.

O terceiro complemento ao regime simples de regras primárias, destinado a remediar a ineficácia da pressão social difusa, implica a inserção de regras de julgamento "que dão poder aos indivíduos para proferir determinações dotadas de autoridade respeitantes a questão sobre se, numa ocasião concreta, foi violada uma regra primária". ${ }^{6}$ Além de identificar os indivíduos que devem julgar a matéria posta em questão, estas regras também estabelecem um processo.

Enfim, na combinação de dois diferentes tipos de regras - primárias de obrigação e secundárias (de reconhecimento, modificação e julgamento) - Hart vislumbra a chave para a ciência do direito, o ponto central para a elucidação da estrutura do ordenamento jurídico.

\footnotetext{
${ }^{4}$ HART, op. cit., p. 104.

${ }^{5}$ Ibid., p. 105.

${ }^{6}$ Ibid., p. 106.
} 


\subsection{O PONTO DE VISTA INTERNO DO SISTEMA JURÍDICO: DIFERENÇA ENTRE "TER UMA OBRIGAÇÃO" E "SER OBRIGADO"}

Em contraposição às teorizações de Hans Kelsen, em que o conceito de sanção é essencial para a compreensão do fenômeno jurídico, ${ }^{7}$ Hart dedica uma especial atenção para o aspecto interno do sistema jurídico, ocupando o conceito de obrigação papel central nas elaborações teóricas do referido autor. Isto porque, para Hart, o estudo do direito perpassa necessariamente a visão do participante da comunidade. O aspecto interno das regras é sobremaneira importante, pois implica em considerar a maneira como o grupo contempla sua própria conduta, ao passo que, do ponto de vista externo, somente se afigura possível visualizar a maneira como as regras funcionam na vida dos membros do grupo.

Dentro de sua concepção de direito, Hart entende ser absolutamente necessário que as pessoas aceitem a regra como norma de comportamento e a tenham como um padrão geral aceito pelo grupo. Assim, a violação de uma regra, sob o ponto de vista interno da comunidade, não é apenas a base para a predicação de que sobrevirá uma sanção, mas sim um motivo para hostilidade que justifica a aplicação da regra. Nas palavras de Hart:

O que o ponto de vista externo, que se limita a regularidades observáveis de comportamentos, não pode reproduzir, é o modo pelo qual as regras funcionam relativamente às vidas daqueles que são normalmente a maioria da sociedade. [...] Para eles, a violação da regra não é apenas uma base para a predição de que se seguirá uma reação hostil, mas uma razão para a hostilidade. ${ }^{8}$

Daí que seja possível estabelecer uma distinção entre "ter uma obrigação" e

${ }^{7}$ Segundo o pensador austríaco, "o direito é concebido como uma ordem de coerção, isto é, como uma ordem estatuidora de atos de coerção, então a proposição jurídica que descreve o direito toma a forma da afirmação segundo a qual, sob certas condições ou pressupostos pela ordem jurídica determinados, deve executar-se um ato de coação, pela mesma ordem jurídica especificado" (KELSEN, Hans. Teoria pura do direito. Trad. João Baptista Machado. 6. ed. São Paulo: Martins Fontes, 1998, p. 121).

${ }^{8}$ HART, op. it., p. 100. 
"estar obrigado", pois enquanto "ser obrigado" é uma afirmação normalmente associada a motivos de obediência, isto é, à crença de um sujeito acerca de que algum mal lhe será afligido caso não se comporte de acordo com um comando; o enunciado "ter uma obrigação" independe de motivações psicológicas e pressupõe um contexto de uso referido institucionalmente, um sistema de convenções acordado pela coletividade. ${ }^{9}$ A partir disso, Hart assevera que, ao menos em relação ao direito, o ponto de vista determinante é o do interprete, ou seja, da pessoa que interiorizou a pauta de atuação contida na norma e, portanto, "tem uma obrigação".

Assim, se a abordagem kelseniana do direito aparenta um maior comprometimento com a relação sujeito e objeto, em que as pessoas obedecem porque têm acesso ao conteúdo exterior da norma que prescreve comportamentos e sanções; para Hart, o fator fundamental é a mediação entre os próprios participantes da comunidade (relação sujeito - sujeito) em que, a partir das práticas sociais vigentes, a norma é internalizada. Afastando-se do neopositivismo lógico, Hart enxerga o problema da obrigatoriedade jurídica como um fato institucional, relacionado à prática efetiva do participante dentro do grupo social. ${ }^{10}$

\subsection{A REGRA DE RECONHECIMENTO}

Este hiato enunciado por Hart entre o mero constrangimento e o que venha a ser uma obrigação imposta pelo direito positivo está diretamente relacionado com o problema da fundamentação ético-teórica do direito ou, mais especificamente, à questão de se determinar o porquê da obrigatoriedade jurídica. E, dentro de um sistema jurídico, a primeira questão a ser desenvolvida por qualquer estudioso refere-se à

${ }^{9}$ KOZICKI, Katya.H. L. A. Hart: a hermenêutica como via de acesso para uma significação interdisciplinar do Direito. Universidade Federal de Santa Catarina, Florianópolis, 1993. Dissertação (Mestrado em Filosofia do Estado e do Direito), p. 62-64.

${ }^{10}$ Ibid., p. 49. 
maneira pela qual se revela possível reconhecer, antes de qualquer coisa, quais condutas são (ou não são) juridicamente exigidas. ${ }^{11}$

Neste diapasão, a abordagem hartiana identifica a regra secundária de reconhecimento como elemento apto a discriminar quais regras primárias de obrigação são válidas. Contudo, a questão apresenta relativa complexidade, na medida em que os sistemas jurídicos modernos são dotados de uma pluralidade de fontes, em que a autoridade pode variar. Em tais sistemas, a referida autoridade pode derivar da referência a um texto legal, da sanção legislativa, da prática consuetudinária, das declarações gerais de vontade emitidas por pessoas especificadas, etc.

É ainda por meio da regra de reconhecimento que se resolve o problema da validez jurídica, pois, segundo o próprio Hart, "dizer que uma dada regra é válida é reconhecê-la como tendo passado todos os testes facultados pela regra de reconhecimento e, portanto, como uma regra do sistema". ${ }^{12}$ Todavia, muito embora o reconhecimento de uma regra como válida implique certa aceitação, Hart adverte que é errôneo afirmar que os enunciados de validez significam que a regra é eficaz, dissociando os conceitos de validade e eficácia.

Portanto, a regra de reconhecimento é o critério e a regra última de todo ordenamento jurídico, em que pese não signifique isto que não contenha limitações. A idéia de um critério supremo não se confunde com um critério ilimitado, porque a regra de reconhecimento pode conter em si limitações de ordem jurídica, como a irrevogabilidade dos direitos fundamentais. Ademais, a regra de reconhecimento é direito porque traz em seu bojo as características definitórias do sistema jurídico, bem como não é uma hipótese, devendo ser aceita e posta em prática.

De qualquer forma, as questões acima assinaladas farão com que a Rule of Recognition e a Grundnorm, muito embora ligadas ao papel de atribuir validade às demais normas, assumam conformações distintas nas teorias, respectivamente, de Hart e de Kelsen. Na concepção kelseniana, a norma fundamental é pressuposta, não é

\footnotetext{
${ }^{11}$ KOZICKI, Katya. H. L. A. Hart..., p. 84.

${ }^{12}$ HART, op. cit., p. 114.
} 
dada, mas pensada, a partir de fora do sistema; trata-se, sobretudo, de uma hipótese, cuja validade não pode ser colocada em dúvida. Já no pensamento hartiano, a regra de reconhecimento não é uma hipótese, não tem sua validez desde sempre admitida ou pressuposta sua existência, porque ela efetivamente existe, é direito e é fato; em verdade, não apenas a existência da regra de reconhecimento é uma questão empírica, como, dentro da classificação entre regras primárias e secundárias, Hart localiza a regra de reconhecimento como uma norma secundária.

\subsection{A TEXTURA ABERTA DO DIREITO}

A idéia de textura aberta do direito, em Hart, nasce da premissa de que existem áreas de conduta não completamente abarcadas pelo conteúdo de uma regra. Neste caso, os Tribunais exerceriam a importante função de encontrar uma solução para o caso concreto, à luz das circunstâncias que lhes são apresentadas. Dito de outra forma, sempre existirão casos não regulados pelo direito ou, ainda, regulados de forma insatisfatória, hipótese em que os Tribunais estão legitimados a exercer uma função criadora do direito. ${ }^{13}$

Mas como Hart chega a tal conclusão? Como foi asseverado anteriormente, Hart confere especial atenção ao ponto de vista interno do sistema jurídico, isto é, à relação sujeito-sujeito que faz do direito um fato institucional, reconhecido pelos partícipes da comunidade. Para tanto, Hart se vale dos pressupostos teóricos fornecidos pela Filosofia da Linguagem Ordinária, afirmando que os principais enunciados jurídicos são compreendidos de forma mais satisfatória quando seu significado é reportado a um contexto de uso ou a uma prática institucional vigente.

Contudo, em todos os campos da experiência há um limite insuperável que diz respeito à natureza da linguagem e à orientação que esta poder oferecer. Poderão

\footnotetext{
${ }^{13}$ Ibid., p. 148-149.
} 
sempre surgir incertezas relativamente à aplicabilidade de qualquer regra, pois sempre existirão possibilidades em que um conceito não foi trabalhado, afinal "os legisladores humanos não podem ter conhecimento de todas as possíveis combinações de circunstâncias que o futuro pode trazer". ${ }^{14}$ Esta incapacidade de antecipar a forma pela qual a regra se aplica em todos os casos concretos acarreta uma relativa indeterminação que será coloca diante do juiz.

Surge, então, o problema de saber como deve o juiz se portar quando o imediato enquadramento de uma regra a um caso concreto resulta duvidoso. A resposta oferecida por Hart a esta questão não destoa de uma proposição relativamente comum entre os autores do chamado positivismo jurídico. Em verdade, nos casos em que o juiz não tem condições para decidir com base no direito preexistente, concederse-ia ao magistrado um poder discricionário, autorizando a criação de um direito que lhe permita a atuação, para que não se vejam frustradas as expectativas do jurisdicionado. ${ }^{15}$

Sem embargo, muito embora Hart reconheça o poder discricionário dos Tribunais em alguns casos, faz-se mister ressaltar que a atuação discricionária do magistrado sofre inúmeras restrições relativas às pautas de comportamento já existentes no ordenamento jurídico como um todo. Portanto, ao se valer deste poder discricionário, o juiz não o faz como um legislador, pois se trata, em realidade, de uma atividade destinada ao suprimento lacunas, que importa necessariamente o reconhecimento de que o poder discricionário é limitado pelo direito preexistente. Ou seja, na abordagem hartiana, a "liberdade de criar o direito novo está limitada pelo direito preexistente". ${ }^{16}$

\footnotetext{
${ }^{14}$ HART, op. cit., p. 141.

${ }^{15}$ KOZICKI, Katya. Conflito e estabilização..., p. 173.

${ }^{16}$ Ibid., p. 174.
} 


\section{RONALD DWORKIN: O IMPÉRIO DO DIREITO}

Sucessor da cátedra ocupada por Hart em Oxford, Dowrkin tornou-se um de seus maiores críticos, embora nunca tenha deixado de reconhecer o valor da teoria hartiana. Dworkin afirmou por diversas vezes que a sua filosofia jurídica tinha a finalidade aberta de superar as limitações do positivismo, espaço dentro do qual Hart teria elaborado a mais bem acabada teoria, especialmente no âmbito do common law. Também influenciado pela filosofia da linguagem, Dworkin parte da premissa de que a hermenêutica pode ser utilizada não apenas para descrever o direito, mas para situá-lo dentro de um contexto maior, no qual não faria sentido sua separação em relação às esferas da moral e da política.

Para ressaltar o caráter aberto da interpretação e do sistema jurídico, Dworkin se vale dos chamados casos difíceis (hard cases), em que o sentido de uma norma não está claro ou há uma aparente divergência entre dois comandos legais, não se olvidando ainda da hipótese em que inexiste regulação jurídica para a situação. Nestes casos, os princípios desempenham um papel essencial, ponto que teria passado em branco na abordagem hartiana do fenômeno jurídico. Dworkin nega a tese da discricionariedade judicial, afirmando que, nestas circunstâncias, o juiz não cria o direito, mas recorrerá a princípios implícitos nas regras de maneira a reconstruir interpretativamente o direito da melhor forma possível. Tal tarefa, levada a efeito através da metáfora do Juiz Hércules, encerra por encontrar uma resposta já latente no ordenamento jurídico, evitando, assim, a elaboração de um direito ex post facto.

As teorizações de Dworkin podem ser resumidas e divididas segundo suas três teses fundamentais: (i) a tese dos direitos (the right thesis); (ii) a tese da resposta correta (the right thesis ansewer); e (iii) a tese do direito como integridade (law as integrity). Porém, antes de avançar sobre o estudo destas teses, convém analisar melhor as críticas feitas por Dworkin a Hart, pois estas não apenas delimitarão sua proposta de compreensão do mundo jurídico, como servem de introdução ao seu pensamento em geral. 


\subsection{AS CRÍTICAS DE DWORKIN AO POSITIVISMO}

Em que pese tenha sido John Austin quem primeiramente difundiu um conjunto de idéias que Dworkin denomina por "positivismo jurídico", não é possível deixar de reconhecer que, em verdade, foi o Professor H. L. A. Hart, ao expô-las com "clareza e elegância", quem conferiu solidez especial e uma forma poderosa a este tipo de abordagem do direito. ${ }^{17} \mathrm{O}$ positivismo jurídico, bem como a teoria de Hart, pode ser enunciado a partir de alguns preceitos-chave, ${ }^{18}$ que segundo Dworkin seriam os seguintes:

(i) o direito de uma comunidade consiste num conjunto de regras especiais que determina quais comportamentos podem ser coagidos pelo poder público; tais regras especiais podem ser identificadas com o auxílio de critérios específicos, que nada têm a ver com seu conteúdo, mas sim com o seu pedigree, ou seja, com a maneira pela qual foram formuladas;

(ii) o conjunto destas regras é coextensivo com "o direito", de modo que caso alguma hipótese não esteja enquadrada nestas regras, o caso apreciado não será decidido pela "aplicação do direito", mas sim pelo "discernimento pessoal" de uma autoridade pública competente;

(iii) dizer que alguém tem uma "obrigação jurídica" significa dizer que seu caso se enquadra numa regra jurídica válida que exige uma ação ou omissão; na ausência de tal regra jurídica, o juiz decide com discrição, não fazendo valer um direito subjetivo correspondente à matéria questionada.

Para refutar estas proposições Dworkin lança um ataque geral ao positivismo, afirmando que quando os juízes debatem a respeito de direitos e obrigações jurídicas particularmente naqueles casos difíceis, momento em que estes conceitos parecem mais frágeis -, eles recorrem a padrões que não funcionam como regras, mas operam

${ }^{17}$ DWORIN, Ronald. Levando os direitos a sério. Trad. Nelson Boeira. São Paulo: Martins Fontes, 2002. p. 27.

${ }^{18}$ Ibid., p. 27-29. 
diferentemente, como princípios, políticas ou outros tipos de padrões. Tais padrões fazem parte do direito, sendo este um sistema composto de regras e princípios. Princípio, numa acepção ampla, pode englobar um padrão econômico, moral ou político, porém numa acepção estrita, a qual Dworkin dá preferência, é uma exigência de justiça e eqüidade que pode englobar aspectos morais. ${ }^{19}$

A diferença entre princípios e regras jurídicas é de natureza lógica. Os dois conjuntos de padrões apontam para decisões particulares acerca da obrigação jurídica em circunstâncias específicas, mas as regras aplicam-se à maneira do "tudo ou nada" ou a regra é válida e se aplica, ou não é válida -, já os princípios não apresentam conseqüências jurídicas previamente determinadas, mas enunciam uma razão que conduz um argumento em certa direção, conferindo uma especial atenção à dimensão do peso ou importância. ${ }^{20}$ Dworkin assevera que os positivistas ignoram o fato de que uma constelação de princípios pode gerar uma obrigação, bastando que existam para isso fortes razões a sustentar a existência de tal obrigação. ${ }^{21}$

Por ignorarem o fato de que os princípios criam obrigações, os positivistas incorrem numa outra confusão entre o que seja afirmar que alguém tem poder discricionário num sentido fraco (ex.: hipótese em que um sargento é chamado a escolher os seus cinco melhores soldados) e que alguém tem poder discricionário num sentido forte (ex.: hipótese em que um sargento é chamado a escolher quaisquer cinco soldados dentre seus homens). Uma autoridade pública, mesmo diante da ausência de regras, jamais poderá julgar de maneira negligente ou mal-intencionada, estando sujeita aos padrões de bom senso e eqüidade, que fazem parte do direito. Dworkin assevera que os positivistas acreditam que a doutrina do poder discricionário seja um insight, quando na verdade é uma tautologia: implica em reconhecer que o juiz não está sujeito a qualquer padrão jurídico. ${ }^{22}$

\footnotetext{
${ }^{19}$ Ibid., p. 36.

${ }^{20}$ Ibid., p. 36-42.

${ }^{21}$ Ibid., loc. cit.

${ }^{22}$ Ibid., p. 50-55.
} 
De outra parte, se os princípios são pertencentes à esfera do direito, não há como preservar a noção de uma regra suprema capaz de formular um teste de pedigree que possa ser satisfeito por todos os princípios. Segundo Hart, a maioria das regras de direito seriam válidas porque alguma instituição competente as promulgou. Todavia, a origem dos princípios não se encontra na promulgação de uma lei, mas na compreensão do que é apropriado, desenvolvida pelos juristas e pelo público em geral, ao longo do tempo. A continuidade de seu poder depende da manutenção desta compreensão do que é apropriado, sequer podendo se falar em "anulação ou revogação" de princípios. ${ }^{23}$

Por derradeiro, Dworkin assinala que até mesmo a idéia de existência desta regra suprema (a regra de reconhecimento em Hart) é falha. Para tanto afirma que vários positivistas, dentre eles Hart, reconhecem a possibilidade de se designar por direito não apenas regras promulgadas por instituições, mas também regras reconhecidas pelo costume. Não obstante, se a própria regra suprema afirma que outras regras aceitas pela sociedade são igualmente obrigatórias, então ela não fornece um teste diverso do que se poderia aplicar sem a sua existência. O tratamento dado ao costume por estes autores equivaleria a uma confissão de que algumas regras de direito são aceitas não pelo padrão estabelecido pela regra suprema e sim porque são aceitas pela comunidade, caindo por terra a arquitetura jurídica piramidal do positivismo. ${ }^{24}$

\subsection{A TESE DOS DIREITOS}

Como especificado anteriormente, no centro da teoria de Dworkin está a noção de princípio que pode ser apreendida de uma dupla maneira: "internamente em oposição à de política, consubstanciando o nervo da teoria da adjudication em

\footnotetext{
${ }^{23}$ Ibid., p. 64.

${ }^{24}$ Ibid., p. 66-69.
} 
Dworkin e, externamente, em oposição à regra jurídica, determinando o debate com o positivismo de Hart [...]". ${ }^{25}$ Portanto, muito embora Dworkin estabeleça uma conexão forte entre direito e moral, é fundamental para compreender o pensamento deste autor estudar a distinção entre argumentos de princípios e argumentos de política.

Os argumentos de política justificam uma decisão política, mostrando que a decisão fomenta ou protege algum objetivo da comunidade como um todo. Um argumento de política pode ser facilmente visualizado no ato de concessão de um subsídio para a indústria aeronáutica, informado pela idéia de que tal subvenção irá proteger a defesa nacional. Já os argumentos de princípio justificam uma decisão política, mostrando que a decisão respeita ou garante um direito de um indivíduo ou de um grupo. O argumento segundo o qual uma minoria não pode ser discriminada, tendo direito à igual consideração e respeito, é um argumento de princípio. ${ }^{26}$

Isto é absolutamente importante dentro da linha de raciocínio traçada por Dworkin, pois levará o autor em questão a afirmar que os direitos fundamentais são trunfos, prerrogativas decorrentes dos princípios da comunidade, que podem ser invocados até mesmo contra o princípio majoritário. Ora, é natural que o Poder Legislativo, dentro de sua competência, venha a aderir a argumentos de política e adote programas decorrentes de tais argumentos. ${ }^{27}$

Entretanto, se os Tribunais fossem legisladores delegados, seria forçoso reconhecer que teriam competência para fazer o mesmo. Mas isto não ocorre, os juízes não são e nem devem ser legisladores delegados e, por isso mesmo, decidem segundo argumentos de princípio, ainda que tais argumentos tenham sido gerados por uma lei baseada em critérios políticos. ${ }^{28}$ Daí que legisladores e juízes cumpram funções diferentes numa comunidade de princípios: as leis são criadas pelos legisladores tendo em vista o bem-estar da comunidade em geral, mas a ausência de limites que são dados

\footnotetext{
${ }^{25}$ CHUEIRI, Vera Karam de. Filosofia do direito e modernidade: Dworkin e a possibilidade de um discurso instituinte de direitos. Curitiba: JM, 1995, p. 73.

${ }^{26}$ DWORIN, Ronald. Levando os direitos..., p. 129-130.

${ }^{27}$ Ibid., p. 130.

${ }^{28}$ Ibid., p. 131-132.
} 
pelos direitos individuais (a serem reconhecidos pelos juízes) faz com que o princípio majoritário degenere numa ditadura da maioria.

A tese sustentada por Dworkin é de que, mesmo nos casos difíceis, as decisões judiciais devem se pautar por argumentos de princípio e não de política, pois assim gozam de muito mais força. Afinal, uma decisão baseada em princípios não é facilmente objetável por motivos de política, uma vez que a dimensão política lhe atribuiria caráter imediatista e casuístico, ao passo que a fundamentação a partir de princípios faz com que o próprio direito individual configure o sentido e a razão de ser da decisão. ${ }^{29}$

\subsection{A TESE DA RESPOSTA CERTA}

Ao longo do tópico anterior restou evidenciado que a tese dos direitos está fincada na premissa de que os juízes decidem os casos difíceis por meio da confirmação ou negação de direitos concretos e não criando um novo direito que se aplica retroativamente. Contudo, estes direitos concretos nos quais os juízes de apóiam, os quais podem ser aferidos a partir de argumentos de princípio, devem ser institucionais e não circunstanciais. ${ }^{30}$

Portanto, o fato de algumas instituições serem totalmente autônomas traz a conseqüência de que os direitos institucionais que ela reconhece são direitos genuínos, verdadeiros trunfos. Disto decorre a tese da resposta correta: a autonomia da comunidade de princípios insula o dever de uma autoridade pública da maior parte de moralidade institucional possível. O juiz não é livre para pôr em prática suas convicções pessoais ao decidir um caso difícil, pois não apenas sofre restrições institucionais como as partes têm o direito legítimo de esperar que o juiz faça uso do

\footnotetext{
${ }^{29}$ CHUEIRI, op. cit., p. 75.

${ }^{30}$ DWORIN, Ronald. Levando os direitos..., p. 158.
} 
seu melhor julgamento. ${ }^{31}$

Na visão de Dworkin, as partes efetivamente têm direito ao melhor juízo do magistrado sobre a verdadeira natureza de seus direitos, em que pese isso não signifique que as normas jurídicas sejam exaustivas e não ambíguas. Na realidade, a proposição de que existe uma "resposta certa" implica numa complexa referência às responsabilidades dos juízes e das partes. Se a decisão de um caso difícil deve ser uma decisão sobre direitos das partes, nas razões despendidas pela autoridade para justificar seu juízo, deve estar contida uma teoria geral que reconhece ou nega um direito. ${ }^{32}$

Pensando que uma decisão sobre um caso difícil é uma decisão sobre os direitos que as partes efetivamente têm, Dworkin supõe também que esta teoria geral aceita pelo magistrado deverá demonstrar de forma inequívoca qual resposta é exigida pelo caso difícil. Todavia, isto acarreta ainda uma outra conclusão: a de que as partes e os julgadores estão adstritos não apenas a um conjunto de regras, mas a um empreendimento, que tem caráter próprio. Melhor dizendo: os atores do sistema jurídico estão envolvidos num empreendimento coletivo de longa duração e deve existir uma racionalidade específica para este tipo de projeto. ${ }^{33}$

Dworkin vislumbra o exemplo de uma cadeia literária, situação em que vários autores escrevem um livro (um romance) que nunca chega ao seu fim ou nunca é concluído. As pessoas que iniciaram a construção do texto literário certamente não poderão ser consultadas como fontes de uma verdade ahistórica sobre o livro, bem como se está diante de um romance sem final definido. Assim, para que a tese da resposta certa seja viabilizada, os juízes devem encarar sua decisão como um capítulo a mais de uma história já iniciada por outros. Cada juiz deve fazer da sua decisão a melhor possível naquele momento, mas não pode romper com a unidade e coerência da história já iniciada: tal qual o escritor literário deve levar em conta características deste projeto em desenvolvimento, como, por exemplo, gênero, temática, personagens,

\footnotetext{
${ }^{31}$ Ibid., p. 159-162.

${ }^{32}$ Ibid., p. 163.

${ }^{33}$ Ibid., p. 164.
} 
etc. $^{34}$

Esta dinâmica interpretativa, denominada por Dworkin de chain of law, permite que certas práticas passem por um processo de interpretação, gerando outras novas que, no futuro, poderão ser re-interpretadas, e assim por diante. Mas o juiz não cria ou inventa nada, ele descobre quais padrões melhor expressam uma comunidade, quais se encaixam com aquilo que os juízes fizeram no passado, quais são adequados ao princípio da igualdade. Enfim, esta tarefa criativa apenas impõe uma justificativa para o texto interpretado que não poderia faltar ao magistrado em seu mister.

\subsection{O DIREITO COMO INTEGRIDADE}

Com efeito, é possível afirmar que em seu livro "O Império do Direito", Dworkin altera um pouco seu enfoque, demonstrando não mais tanta preocupação em rebater a tese da discricionariedade judicial, mas sim em encontrar uma justificativa para a relação entre as decisões passadas e o uso da força. Ou seja, Dworkin procura elaborar uma concepção de direito que possa explicar de que modo aquilo que se chama comumente de direito oferece uma justificativa plausível para o exercício geral do poder coercitivo pelo Estado. ${ }^{35}$ E a melhor concepção de direito para explicar sua função controladora do poder político seria a do "direito como integridade".

Assim, Dworkin procura demonstrar que uma sociedade política que aceita a integridade como virtude política adquire uma forma muito especial de comunidade, no sentido de que promove a autoridade moral do direito para assumir e mobilizar o monopólio da força coercitiva. Para isso Dworkin imagina três modelos de comunidade:

\footnotetext{
${ }^{34}$ CHUEIRI, op. cit., p. 98-99.

35 DWORIN, Ronald. O império do direito. Trad. Jefferson Luiz Camargo. São Paulo: Martins Fontes, 1999, p. 231.
} 
(i) o primeiro supõe que os membros de uma comunidade tratam sua associação apenas como um acidente de fato da história ou da geografia (ex.: dois náufragos numa mesma ilha) e que, portanto, padeceriam de uma convivência forçada, não se verificando um verdadeiro sentimento associativo; ${ }^{36}$

(ii) o segundo modelo apresentado é o de uma comunidade de "regras", em que seus membros aceitam o compromisso geral de obedecer às regras estabelecidas de modo específico por esta comunidade, porém negam que estas regras foram negociadas com base num compromisso comum com princípios subjacentes que são, eles próprios, fontes de obrigação; ${ }^{37}$

(iii) o terceiro modelo associativo é o da comunidade de princípios, na qual as pessoas aceitam que são governadas por princípios comuns e não apenas por regras criadas por um acordo político. Para tais pessoas, a política tem natureza diferente: é uma arena de debates sobre quais princípios a comunidade deve adotar como sistema, que concepção se que deve ter de justiça, eqüidade, devido processo legal, etc. ${ }^{38}$

Portanto, os membros dessa comunidade de princípios admitem que seus direitos e deveres políticos não se esgotam nas decisões particulares tomadas por suas instituições políticas, mas dependem do sistema de princípios que essas decisões pressupõem e endossam. Logo, cada membro aceita que os outros têm direitos e que eles têm deveres que decorrem desse sistema, ainda que estes nunca tenham sido formalmente identificados. $^{39}$

A comunidade de princípios parece ser a que melhor acolhe o ideal de integridade, pois nela cada pessoa aceita a integridade política como um ideal político distinto, e trata a aceitação geral desse ideal, mesmo entre pessoas que de outra forma estariam em desacordo sobre a moral política. Em suma, por ser uma comunidade democrática, tem um argumento melhor em favor da legitimidade do que uma

\footnotetext{
${ }^{36}$ Ibid., p. 251-252.

${ }^{37}$ Ibid., p. 253-254.

${ }^{38}$ Ibid., p. 254-255.

${ }^{39}$ Ibid., p. 256.
} 
comunidade que não aceite a integridade como um ideal político, uma virtude.

Dworkin relaciona a integridade com a eqüidade, a justiça e o devido processo legal, no sentido de que são princípios políticos que conferem força às leis editadas pelas autoridades legislativas, bem como devem ser reconhecidos como princípios morais necessários à justificação das decisões judiciais. Todavia, não são raros os casos em que a eqüidade e a justiça entram em conflito, tornando-se difícil também aplicação do devido processo legal. Nestas hipóteses, a integridade funciona como um agente externo, independente e ideal, sendo possível que as pessoas venham a divergir sobre a justiça e a eqüidade, porém não sobre a integridade, que será usada como parâmetro para a decisão. ${ }^{40}$

\section{4 À GUISA DE CONCLUSÃO: ASPECTOS POSITIVOS E NEGATIVOS DE CADA PROPOSTA}

Ambas as teorias estudadas propiciaram inúmeros avanços na forma de compreensão do fenômeno jurídico, todavia nenhuma delas é imune a críticas, podendo levantar-se sérias ressalvas com relação à sua adoção irrestrita. Resta, então, analisar, de maneira breve, os aspectos positivos e negativos das construções teóricas em questão.

Primeiramente, é preciso registrar que Hart se distancia das formulações clássicas do positivismo jurídico, aproximando o direito da práxis social e de sua natureza hermenêutica, o que encerra na revisão do conceito de sistema jurídico fechado. Não obstante, em que pese sua preocupação com o aspecto interno do direito, ou seja, com a interiorização e aceitação da norma jurídica pelos membros da comunidade, a leitura que Hart faz do direito (ou, pelo menos, do conceito de direito) é essencialmente descritiva, não se percebendo uma preocupação com o conteúdo da norma. 
Como assevera Luis Prieto Sanchís, "el concepto de aceptacíon no requiere nada más que la norma, en cuanto tal, constituye para quien la acepta una razón para un comportamiento conforme la norma". 41 Dito de outro modo, a aceitação do direito independe do conteúdo das normas jurídicas, daí porque, muito embora Hart negue esta possibilidade, seja possível imaginar um conhecimento sem aceitação, na visão de um observador externo não-extremado. ${ }^{42}$

A teoria hartiana, em síntese, não identifica qualquer comprometimento entre o direito e a realização da justiça material, sendo a norma jurídica ainda concebida sob um aspecto formal, sem preocupação de conteúdo. Tal problema é fruto de grande parte das preocupações de Dworkin, que procura fundar o direito sob a idéia de uma comunidade de princípios, sendo estes entendidos como máximas de justiça, de eqüidade e do devido processo legal, capazes de serem levantados mesmo contra o princípio majoritário.

Dworkin aponta para a moralidade ínsita à função jurisdicional, salientando que as partes efetivamente têm direito ao melhor juízo do magistrado sobre a demanda que lhe é apresentada; como, aliás, não poderia deixar de ser. E, para justificar seu juízo, deve não apenas a autoridade fundamentar satisfatoriamente sua decisão - o que encontra amparo num dever geral de fundamentação vigente em todos os sistemas processuais hodiernos - como deve valer-se de uma teoria geral que reconhece ou nega um direito, reduzindo significativamente a discricionariedade judicial. Em caso de dúvida, decide o juiz segundo princípios, que fazem parte do direito.

Sem embargo, ao negar a tese da neutralidade, apregoando uma conexão necessária entre Direito e Moral, talvez Dworkin tenha contribuído para uma certa "epidemia de sinceridade", oferecendo respaldo ou cobertura teórica para dizer com um refinamento teórico que os conflitos jurídicos se resolvem com respostas morais.

${ }^{40}$ Ibid., p. 213-215.

${ }^{41}$ SANCHÍS, Luis Prieto. Constitucionalismo y positivismo. 2. ed. México D.F.: Fontamara, 1999, p. 61.

${ }^{42}$ MacCormick, Neil. Regras Sociales. H.L.A. HART y el concepto de derecho. Apud: KOZICKI, Katya. Conflito e estabilização ..., p. 176. 
Ao "juridicizar" a moral, não teria Dworkin ocultado o fato de que o direito é mais vontade do que razão, mais poder do que verdade? Não seria melhor admitir que os juízes são titulares de um poder de decisão - que, sob certo aspecto, encerra uma discricionariedade -, fazendo com que a opinião moral externa, daqueles que não fazem parte do Poder Judiciário, tivesse mais valor para decidir efetivamente o que é justo?

Acaso se admita que se tem de aceitar a existência de uma moralidade intrínseca às decisões judiciais, a teoria dos princípios representa mesmo um chamamento à responsabilidade moral e política do interprete ou o sinal de sua decadência? Enfim, ao que parece, a polêmica entre Herbert Hart e Ronald Dworkin, longe de encerrar um capítulo da Teoria do Direito, ainda representa um tema capaz de suscitar inúmeras dúvidas e controvérsias.

\section{REFERÊNCIAS}

CHUEIRI, Vera Karam de. Filosofia do direito e modernidade: Dworkin e a possibilidade de um discurso instituinte de direitos. Curitiba: JM, 1995.

DWORIN, Ronald. Levando os direitos a sério. Trad. Nelson Boeira. São Paulo: Martins Fontes, 2002.

Fontes, 1999.

. O império do direito. Trad. Jefferson Luiz Camargo. São Paulo: Martins

HART, H. L. A. O conceito de direito. Trad. A. Ribeiro Mendes. 2. ed. Lisboa: Caloustre Gulbenkian, 1994.

KELSEN, Hans. Teoria pura do direito. Trad. João Baptista Machado. 6. ed. São Paulo: Martins Fontes, 1998.

KOZICKI, Katya. Conflito e estabilização: comprometendo radicalmente a aplicação do direito com a democracia nas sociedades contemporâneas. Universidade Federal de Santa Catarina, Florianópolis, 2000. Tese (Doutorado em Filosofia do Estado e do Direito). 
H. L. A. Hart: a hermenêutica como via de acesso para uma significação interdisciplinar do Direito. Universidade Federal de Santa Catarina, Florianópolis, 1993. Dissertação (Mestrado em Filosofia do Estado e do Direito).

SANCHÍS, Luis Prieto. Constitucionalismo y positivismo. 2. ed. México D.F.: Fontamara, 1999. 